\title{
Effect of clofazimine and dapsone on rifampicin (Lositril) pharmacokinetics in multibacillary and paucibacillary leprosy cases
}

\author{
J MEHTA,* I S GANDHI $\dagger$, S B SANE $\ddagger \&$ \\ M N WAMBURKAR† \\ *Poona District Leprosy Committee, 16 B-1, Dr Ambedkar Road, \\ Pune 411 001, India; †Medical Services, Hindustan Antibiotics \\ Limited, Pimpri, Pune 411 018, India; $\ddagger D r$ Bandorawalla Leprosy \\ Hospital, Pune.
}

\section{Introduction}

WHO Expert Committee on Leprosy has recommended combined chemotherapy for both multibacillary and paucibacillary leprosy cases with an objective of preventing the multiple drug resistance consequent to emergence of wide-spread dapsone resistance (both primary and secondary). It has also been demonstrated that daily administration of $600 \mathrm{mg}$ rifampicin is not more effective than monthly administration of $600 \mathrm{mg}$ on consecutive days. ${ }^{8}$

The peak blood levels of rifampicin in normal adults vary widely from individual to individual and also within the same subject. Peak blood levels occur between 2 and $4 \mathrm{hr}$ following the oral administration of $600 \mathrm{mg}$ dose. The average peak level is $7 \mathrm{mcg}$ per $\mathrm{ml}$; however, the peak level may vary from 4 to $32 \mathrm{mcg}$ per $\mathrm{ml}$. In normal adults the $t \frac{1}{2}$ of rifampicin in blood is approximately $3 \mathrm{hr}$. Elimination occurs mainly through the bile and to a lesser extent by the urine. ${ }^{1}$

Abbreviations used in the article: MCR, metabolic clearance rate $(\mathrm{ml} / \mathrm{mt} / \mathrm{kg}=$ millilitre per minute per kilogram body weight); Ke, rate constant for elimination $\left(\mathrm{h}^{1}=\right.$ rate per hour); Auc, area under curve $(\mu \mathrm{g}-\mathrm{h} / \mathrm{ml}=$ microgram hours per millilitre); Cmax, maximum concentration $(\mu \mathrm{g} /$ $\mathrm{ml}=$ microgram per millilitre); RC, rifampicin + clofazimine; RDC, rifampicin + dapsone + clofazimine; RD, rifampicin + dapsone; $\mathrm{Ka}$, rate constant for absorption $\left(\mathrm{h}^{\mathrm{l}}=\right.$ rate per hour); avd, apparent volume of distribution $(1=$ litre); avd-kg, apparent volume of distribution per kilogram body weight; avd-kg(1), apparent volume of distribution per kilogram body weight expressed in litres; tp, time to reach peak concentration; $t \frac{1}{2}$, half life; and Auc/t $t \frac{1}{2}$, ratio of area under curve to half life. 
To what extent dapsone and clofazimine can affect rifampicin pharmacokinetics has not been studied in cases of multibacillary and paucibacillary leprosy.

\section{Objectives of the present study}

With the following three objectives, the present study was initiated:

1 To determine to what extent the type of leprosy (multibacillary and paucibacillary) can influence pharmacokinetic parameters of rifampicin.

2 To study the influence of following three regimens on the pharmacokinetic parameters of rifampicin (within comparison): (a) rif ampicin + dapsone + clofazimine (RDC); (b) rifampicin + dapsone (RD); and (c) rifampicin + clofazimine (RC).

3 To determine differences in pharmacokinetic parameters of rifampicin within the above three groups, i.e. in between comparison; RDC vs RD; RDC vs RC; and $\mathrm{RD}$ vs $\mathrm{RC}$ ).

\section{Materials and methods}

\section{SUBJECTS}

Male leprosy cases in the age group of 15-60 years were selected. Selection criteria used are enumerated below:

1 Inclusion. a, non-obese patients; $\mathrm{b}$, a confirmed case of multibacillary or paucibacillary leprosy; and c, should not have received any other drugs for at least 2 weeks prior to initiation of the study.

2 Exclusion. a, History of allergy to any one of the drugs in study period, i.e. rifampicin, dapsone and clofazimine; b, patients having any gastrointestinal ulcers and history of gastrectomy; c, patients requiring any other concomitant therapy; and d, patients with any other disease, haematological, renal, cardiovascular or hepatic.

\section{Plan and design}

METHOD

Complete double blind within comparison design was used. A minimum time span of 2 weeks between doses, after an initial 'run in' period of one week, was 
Table 1. Experimental design.

\begin{tabular}{|c|c|c|c|c|c|}
\hline \multicolumn{3}{|c|}{ Pre-regimen phase } & \multicolumn{3}{|c|}{ Post-regimen phase } \\
\hline Week & Day & & Week & Day & \\
\hline \multirow[t]{2}{*}{ I } & Wednesday & $\mathrm{RDC}_{1}: \mathrm{RD}_{1}: \mathrm{RC}_{1}$ & III & Wednesday & $\mathrm{RDC}_{1}: \mathrm{RD}_{1}: \mathrm{RC}_{1}$ \\
\hline & Friday & $\mathrm{RDC}_{2}: \mathrm{RD}_{2}: \mathrm{RC}_{2}$ & & Friday & $\mathrm{RDC}_{2}: \mathrm{RD}_{2}: \mathrm{RC}_{2}$ \\
\hline \multirow[t]{3}{*}{ II } & Monday & $\mathrm{RDC}_{3}: \mathrm{RD}_{3}: \mathrm{RC}_{3}$ & IV & Monday & $\mathrm{RDC}_{3}: \mathrm{RD}_{3}: \mathrm{RC}_{3}$ \\
\hline & Wednesday & $\mathrm{RDC}_{4}: \mathrm{RD}_{4}: \mathrm{RC}_{4}$ & & Wednesday & $\mathrm{RDC}_{4}: \mathrm{RD}_{4}: \mathrm{RC}_{4}$ \\
\hline & Friday & $\mathrm{RDC}_{5}: \mathrm{RD}_{5}: \mathrm{RC}_{5}$ & & Friday & $\mathrm{RDC}_{5}: \mathrm{RD}_{5}: \mathrm{RC}_{5}$ \\
\hline III & Monday & $\mathrm{RDC}_{6}: \mathrm{RD}_{6}: \mathrm{RC}_{6}$ & $\mathrm{~V}$ & Monday & $\mathrm{RDC}_{6}: \mathrm{RD}_{6}: \mathrm{RC}_{6}$ \\
\hline
\end{tabular}

kept. The allocation of drug regimen was based on nature of leprosy. Specimens were code labelled as per master code sheet. Details of experimental design are given in Table 1.

\section{DOSAGE}

'Run in' period. The patients were divided into three groups of six patients each. Physical examination (height, weight and midarm muscle circumference) and laboratory investigations such as bacteriological index, nasal smear, blood (total and differential WBC counts, haemoglobin, haematocrit, bleeding time, coagulation time and platelet count), urine, stool and sputum examination, liver function tests (SGOT, SGPT, alkaline phosphatase and serum bilirubin), were carried out and recorded in the proforma. No drugs were given during this period of one week.

Pre-dose period. Patients were fasted overnight for $8 \mathrm{hr}$ prior to the day of estimating the drug levels. One hour prior to the study, $250 \mathrm{ml}$ of water was given to each of them. They were asked to void urine $15 \mathrm{~min}$ prior to the dose administration.

Dosing. Both multibacillary and paucibacillary cases received $600 \mathrm{mg}$ rifampicin alone at the exact time of drug administration. The time at which rifampicin had been given was recorded for each of the patients.

Post-dosing period. The cases were not given any food during the next $3 \mathrm{hr}$ of the study, but $150 \mathrm{ml}$ of water was given at the end of 1 and $2 \mathrm{hr}$. No strenuous or athletic activity was permissible during the period of study. A light breakfast was given $3 \mathrm{hr}$ after the study, i.e. at $12.15 \mathrm{pm}$.

\section{PHARMACOKINETIC SAMPLING}

A siliconized intravenous catheter was used for withdrawing $3 \mathrm{ml}$ of blood in a 15 $\mathrm{ml}$ code labelled centrifuge tube at $9.00 \mathrm{am}, 10.00 \mathrm{am}, 11.00 \mathrm{am}, 1.00 \mathrm{pm}$ and 3.00 
$\mathrm{pm}$ on the first day and 9.00 am on the next day; i.e. $0,1,2,4,6$ and $24 \mathrm{hr}$ blood samples were collected. Any deviations from the stated sampling times were recorded on the form. For withdrawing blood, Medivik disposable sterile syringes were used. The code labels and code letters were selected by the investigator for each case.

The separated serum was transferred to code labelled vials. The vials were sealed with aluminium seals by a hand-sealing machine. Until the time of transportation, they were kept in a Thermos with ice in the ref rigerator. On the day of transportation, they were taken in the Thermos flask. On the same day the microbiological assay of rifampicin was done by the USP method.

\section{STATISTICAL ANALYSIS}

Using a single compartment pharmacokinetic model the values of $\mathrm{Ka}, \mathrm{Ke}$, Auc, avd $^{-\mathrm{kg}}$, MRC, $t \frac{1}{2}$ tp., Cmax and Auc $/ t \frac{1}{2}$ were calculated. Mean and standard error for the pharmacokinetic parameters were calculated. Student's ' $t$ ' test (two tailed) was used for 'in between comparison' and paired ' $t$ ' test was used for 'within comparison'.

\section{Results}

COMPARISON OF PHARMACOKINETIC PARAMETERS IN MULTIBACILLARY AND PAUCIBACILLARY LEPROSY CASES

No statistically significant difference was noted in rifampicin pharmacokinetic parameters, like $\mathrm{Ka}, \mathrm{Ke}$, Auc, avd ${ }^{-\mathrm{kg}}$, tp, MCR, $t \frac{1}{2}$, Cmax and Auc $/ t_{2}^{\frac{1}{2}}$ in multibacillary and paucibacillary leprosy cases. Apparently the type of leprosy has no effect on rifampicin pharmacokinetics.

\section{EFFECT OF DIFFERENT REGIMENS ON THE RIFAMPICIN PHARMACOKINE- TICS (WITHIN COMPARISON)}

The following observations were noted:

$1 R C$ Group. While comparing 'within patient' data for the pre- and postregimen phases of $\mathrm{RC}$ group, clofazimine was found to reduce the rate of absorption $(\mathrm{Ka})$ of rifampicin $(P<0.01)$ and delay the time to reach the peak serum concentration (tp) $(P<0 \cdot 01)$. However, no statistically significant difference was noted in other pharmacokinetic parameters, i.e. Ke, Auc, avd ${ }^{-k g}, \mathrm{MCR}$, $t \frac{1}{2}, \mathrm{Cmax}$ and Auc $/ t \frac{1}{2}$ ratio.

$2 R D C$ Group. Except for reducing Auc $(P<0 \cdot 05)$, no statistically significant difference in other pharmacokinetic parameters of rifampicin, i.e. $\mathrm{Ka}, \mathrm{Ke}$, avd ${ }^{-\mathrm{kg}}$, MCR, $t \frac{1}{2}$, tp, Cmax and Auc $/ t \frac{1}{2}$ ratio was noted in group RDC. However, $1 \mathrm{~h}$ 
Table 2. Effect of clofazimine, dapsone and combinations (clofazimine plus dapsone) on serum concentration of rifampicin (Lositril).

\begin{tabular}{|c|c|c|c|c|c|}
\hline Group & & $1 \mathrm{~h}$ & $2 \mathrm{~h}$ & $4 \mathrm{~h}$ & $6 \mathrm{~h}$ \\
\hline \multirow[t]{2}{*}{$\mathrm{RDC}$} & Pre & $\begin{array}{c}6 \cdot 15 \pm 1 \cdot 32 \\
(n=6)\end{array}$ & $\begin{array}{c}5 \cdot 52 \pm 6 \cdot 97 \\
(n=6)\end{array}$ & $\begin{array}{c}4 \cdot 9 \pm 0 \cdot 55 \\
(n=6)\end{array}$ & $\begin{array}{c}3 \cdot 81 \pm 0 \cdot 45 \\
\quad(n=6)\end{array}$ \\
\hline & Post & $\begin{array}{c}2 \cdot 66 \pm 1 \cdot 35^{*} \\
(n=6)\end{array}$ & $\begin{array}{c}7 \cdot 02 \pm 0 \cdot 86 \\
(n=6)\end{array}$ & $\begin{array}{c}5 \cdot 43 \pm 0 \cdot 78 \\
(n=6)\end{array}$ & $\begin{array}{c}3 \cdot 34 \pm 0 \cdot 60 \\
(n=6)\end{array}$ \\
\hline \multirow[t]{2}{*}{ RD } & Pre & $\begin{array}{c}6 \cdot 4 \pm 0 \cdot 75 \\
(n=6)\end{array}$ & $\begin{array}{l}5 \cdot 83 \pm 0 \cdot 55 \\
\quad(n=6)\end{array}$ & $\begin{array}{c}4 \cdot 25 \pm 0 \cdot 63 \\
(n=6)\end{array}$ & $\begin{array}{c}3 \cdot 05 \pm 0 \cdot 38 \\
(n=6)\end{array}$ \\
\hline & Post & $\begin{array}{c}3 \cdot 7 \pm 1 \cdot 86 \\
(n=5)\end{array}$ & $\begin{array}{c}7 \cdot 78 \pm 1 \cdot 34 \\
(n=5)\end{array}$ & $\begin{array}{c}4 \cdot 78 \pm 0 \cdot 74 \\
(n=5)\end{array}$ & $\begin{array}{c}3 \cdot 22 \pm 0 \cdot 53 \\
(n=5)\end{array}$ \\
\hline \multirow[t]{2}{*}{$\mathrm{RC}$} & Pre & $\begin{array}{c}3 \cdot 95 \pm 0 \cdot 98 \\
\quad(n=6)\end{array}$ & $\begin{array}{c}5 \cdot 85 \pm 0 \cdot 57 \\
\quad(n=6)\end{array}$ & $\begin{array}{c}5 \cdot 51 \pm 0 \cdot 42 \\
(n=6)\end{array}$ & $\begin{array}{c}3 \cdot 40 \pm 0 \cdot 80 \\
(n=6)\end{array}$ \\
\hline & Post & $\begin{array}{c}3 \cdot 82 \pm 0 \cdot 84 \\
\quad(n=5)\end{array}$ & $\begin{array}{c}5 \cdot 6 \pm 1 \cdot 38 \\
(n=5)\end{array}$ & $\begin{array}{c}5 \cdot 85 \pm 0 \cdot 72 \\
\quad(n=4)\end{array}$ & $\begin{array}{c}4 \cdot 26 \pm 0 \cdot 72 \\
(n=5)\end{array}$ \\
\hline
\end{tabular}

$\mathrm{NB}, \mathrm{n}$, number of patients; RDC, rifampicin + dapsone + clofazimine; RD, rifampicin + dapsone; RC, rifampicin + clofazimine; values are expressed as mean $\pm \mathrm{SE}$.

$* P<0 \cdot 05$.

Paired ' $t$ ' test used for 'within comparison'

serum concentration of rifampicin was significantly reduced in RDC group $(P<0.05)$ in post-regimen phase.

$3 R D$ Group. No statistically significant alteration in any of the pharmacokinetic parameters of rif ampicin was noted in group RD.

COMPARISON OF PHARMACOKINETIC PARAMETERS OF RIFAMPICIN IN PREAND POST-THERAPY PHASES IN VARIOUS GROUPS (IN BETWEEN COMPARISON)

1 While comparing the three groups ('in between patient' data), no statistically significant difference was noted when RDC was compared with RD. In the postregimen phase of $\mathrm{RC}$, the following statistically significant differences in pharmacokinetic parameters of rif ampicin were seen as compared to RDC:

(a) The rate of elimination of rifampicin in $\mathrm{RC}$ was significantly less than in the RDC $(P<0 \cdot 05)$.

(b) The metabolic clearance rate of rifampicin in $\mathrm{RC}$ was significantly less than in the RDC $(P<0 \cdot 02)$

(c) The $t \frac{1}{2}$ of rifampicin in RC was significantly more than in the RDC $(P<0.02)$

(d) The Auc $/ t \frac{1}{2}$ ratio of rifampicin was significantly more in the pre-regimen phase 
Table 3. Effect of clofazimine, dapsone and combination (clofazimine \& dapsone) on pharmacokinetic parameters of rifampicin (Lositril).

\begin{tabular}{|c|c|c|c|c|c|c|c|c|c|}
\hline \multirow{2}{*}{$\begin{array}{l}\text { Therapeutic } \\
\text { regimen }\end{array}$} & \multirow[b]{2}{*}{$\mathrm{n}$} & \multicolumn{2}{|c|}{$\mathrm{Ka}\left(\mathrm{h}^{-1}\right)$} & \multicolumn{2}{|l|}{$\mathrm{Ke}\left(\mathrm{h}^{-1}\right)$} & \multicolumn{2}{|c|}{ Auc $(\mu \mathrm{g}-\mathrm{h} / \mathrm{ml})$} & \multicolumn{2}{|c|}{ avd (1) } \\
\hline & & Pre & Post & Pre & Post & Pre & Post & Pre & Post \\
\hline \multirow[t]{2}{*}{ Group RDC } & 6 & $0 \cdot 650$ & $0 \cdot 436$ & $0 \cdot 159$ & $0 \cdot 209$ & $48 \cdot 55$ & $35 \cdot 43$ & $87 \cdot 74$ & $96 \cdot 19$ \\
\hline & & \pm 0.082 & \pm 0.011 & \pm 0.013 & \pm 0.021 & $\pm 5 \cdot 29$ & $=7 \cdot 45$ & $\pm 17 \cdot 21$ & $\pm 13 \cdot 30$ \\
\hline \multirow[t]{2}{*}{$\mathrm{RD}$} & 5 & 0.675 & 0.522 & $0 \cdot 159$ & $0 \cdot 199$ & $43 \cdot 84$ & $44 \cdot 02$ & $93 \cdot 74$ & $81 \cdot 74$ \\
\hline & & \pm 0.066 & \pm 0.049 & \pm 0.023 & $\pm 0.025 \pm$ & \pm 6.08 & $=8.09$ & $\pm 4 \cdot 13$ & \pm 15.52 \\
\hline \multirow[t]{3}{*}{$\mathrm{RC}$} & 5 & 0.566 & $\dagger 0.389$ & $0 \cdot 191$ & $0 \cdot 165$ & $51 \cdot 05$ & $55 \cdot 23$ & $64 \cdot 69$ & $78 \cdot 88$ \\
\hline & & \pm 0.055 & \pm 0.024 & $\pm 0 \cdot 023$ & $\pm 0.009 \pm$ & $\pm 2 \cdot 48$ & $=7 \cdot 19$ & \pm 6.06 & $\pm 10 \cdot 56$ \\
\hline & & & $d^{-k g(1)}$ & MCR ( & $(\mathrm{ml} / \mathrm{mt} / \mathrm{kg})$ & & $\frac{1}{2}$ & & (h) \\
\hline $\begin{array}{l}\text { Therapeutic } \\
\text { regimen }\end{array}$ & $\mathrm{n}$ & Pre & Post & Pre & Post & Pre & Post & Pre & Post \\
\hline \multirow[t]{2}{*}{ Group RDC } & $\mathrm{n}$ & $1 \cdot 86$ & $2 \cdot 06$ & $0 \cdot 0046$ & 0.0059 & $4 \cdot 51$ & $3 \cdot 44$ & $3 \cdot 09$ & $3 \cdot 46$ \\
\hline & & \pm 0.38 & \pm 0.79 & $\pm 0 \cdot 0006$ & \pm 0.0009 & $\pm 0 \cdot 41$ & $\pm 0 \cdot 30$ & $\pm 0 \cdot 40$ & $\pm 0 \cdot 38$ \\
\hline \multirow[t]{2}{*}{ RD } & 5 & 1.79 & 1.59 & 0.0048 & 0.0049 & $4 \cdot 66$ & $3 \cdot 64$ & $2 \cdot 92$ & $3 \cdot 09$ \\
\hline & & $\pm 0 \cdot 10$ & \pm 0.33 & \pm 0.0009 & \pm 0.0009 & \pm 0.55 & $\pm 0 \cdot 35$ & $\pm 0 \cdot 27$ & $\pm 0 \cdot 27$ \\
\hline \multirow[t]{2}{*}{$\mathrm{RC}$} & 5 & $1 \cdot 27$ & $1 \cdot 47$ & $0 \cdot 0037$ & $0 \cdot 0040$ & $3 \cdot 80$ & $4 \cdot 23$ & $2 \cdot 95$ & $3 \cdot 84$ \\
\hline & & $\pm 0 \cdot 16$ & $\pm 0 \cdot 11$ & $\pm 0 \cdot 0$ & \pm 0.0002 & \pm 0.36 & $\pm 0 \cdot 25$ & $\pm 0 \cdot 16$ & $\pm 0 \cdot 12$ \\
\hline
\end{tabular}

\begin{tabular}{|c|c|c|c|c|c|}
\hline \multirow{2}{*}{$\begin{array}{l}\text { Therapeutic } \\
\text { regimen }\end{array}$} & \multirow[b]{2}{*}{$\mathrm{n}$} & \multicolumn{2}{|c|}{$\mathrm{Cmax}(\mu \mathrm{g} / \mathrm{ml})$} & \multicolumn{2}{|c|}{ Auc $/ t \frac{1}{2}$} \\
\hline & & Pre & Post & Pre & Post \\
\hline \multirow[t]{2}{*}{ Group RDC } & 6 & $6 \cdot 78$ & $5 \cdot 28$ & $11 \cdot 20$ & 10 \\
\hline & & $\pm 0 \cdot 84$ & \pm 0.73 & \pm 1.43 & \pm 1.49 \\
\hline \multirow[t]{2}{*}{$\mathrm{RD}$} & 5 & $6 \cdot 15$ & $8 \cdot 01$ & $9 \cdot 30$ & $12 \cdot 85$ \\
\hline & & \pm 0.26 & $\pm 2 \cdot 3$ & $\pm 0 \cdot 41$ & \pm 3.02 \\
\hline \multirow[t]{2}{*}{$\mathrm{RC}$} & 5 & $7 \cdot 32$ & $6 \cdot 23$ & $13 \cdot 94$ & $12 \cdot 15$ \\
\hline & & $\pm 0 \cdot 25$ & \pm 0.66 & $\pm 1 \cdot 51$ & $\pm 2 \cdot 24$ \\
\hline
\end{tabular}

Values expressed as mean $\pm \mathrm{SE}$; $\mathrm{R}$, rifampicin;

$\mathrm{d}$, dapsone; c, clofazimine.

* Denotes $P<0.05$

$\dagger$ Denotes $P<0.01$

Paired 't' test used for 'within comparison'. 
of $\mathrm{RC}$ than in $\mathrm{RDC}(P<0.05)$; while mean Auc $/ t \frac{1}{2}$ ratio was less in 'post-regimen phase' of RC than 'pre-regimen phase' value and the 'post regimen' mean Auc $/ t \frac{1}{2}$ ratio was more in RD than the 'pre-regimen phase' value; but no statistically significant difference was noted. While dapsone showed the tendency to increase Auc $/ t \frac{1}{2}$ ratio, clofazimine reversed this tendency and the overall effect in the RDC group was the tendency to reduce Auc/ $t \frac{1}{2}$ ratio.

2 While comparing pre-regimen phases of $\mathrm{RD}$ with $\mathrm{RC}$, the following statistically significant differences were noted:

(a) The rate of absorption of rifampicin was significantly less in RC than in RD $(P<0 \cdot 05)$.

(b) The apparent volume of distribution of rifampicin was significantly more in $\mathrm{RD}$ than in $\mathrm{RC}(P<0 \cdot 001)$. The avd $\mathrm{d}^{(1 / \mathrm{kg})}$ was also significantly different in the same way $(P<0 \cdot 01)$.

3 Similar comparison of post-regimen phase of $\mathrm{RD}$ with $\mathrm{RC}$, following changes in the pharmacokinetic parameters of rifampicin were noted:

(a) The rate of absorption of rifampicin was further significantly reduced in RC than in RD. The degree of statistical significance was also increased $(P<0 \cdot 05$ to $P<0 \cdot 01)$.

(b) While the avd in $\mathrm{RD}$ regimen reduced from $93 \cdot 74 \pm 4 \cdot 13$ to $81 \cdot 74 \pm 15 \cdot 52$, it increased in RC regimen from $64 \cdot 69 \pm 6 \cdot 06$ to $78 \cdot 88 \pm 10 \cdot 56$. Hence no statistically significant difference was noted.

(c) The time to reach peak serum concentration (tp) was significantly more in RC than in $\mathrm{RD}(P<0 \cdot 01)$. The $t \frac{1}{2}$ was also increased though not significantly statistically.

(d) While Cmax increased in RD regimen from 6.15 $\pm 0 \cdot 26$ to $8 \cdot 01 \pm 2 \cdot 3$ it declined in $\mathrm{RC}$ from $7 \cdot 32 \pm 0 \cdot 25$ to $6 \cdot 23 \pm 0 \cdot 66$. A similar trend was seen in Auc/ $t \frac{1}{2}$ ratio. Hence no statistically significant difference was noted.

\section{Discussion}

In the present study, rifampicin pharmacokinetics was not affected by the type of leprosy. However, it is evident that the absorption of rifampicin was relatively less than that seen in healthy human volunteers. Whether it is due to reduced gastrointestinal absorption due to the disease per se or due to lower levels of plasma proteins is difficult to say due to the paucity of data for these assumptions.

Viratenen \& Tala $(1974)^{7}$ have reported that prolonged treatment increases the rate of inactivation or elimination of rifampicin. Since rifampicin has been given only as a single dose, the possibility of it per se increasing the rate of its inactivation or elimination is ruled out.

Dapsone did not affect the rifampicin bioavailability, and this finding is 
consistent with experimental observations in mice where no evidence of any antagonism between dapsone and rifampicin has been demonstrated. ${ }^{5}$ Rifampicin is capable of increasing the rate of clearance of dapsone from plasma, possibly secondary to the induction of hepatic microsomal enzymes that may increase $\mathrm{N}$ hydroxylation (which is microsome dependent) instead of increasing the acetylation of dapsone. ${ }^{2,3}$ Furthermore, the levels of dapsone achieved in blood by means of daily doses of $50-100 \mathrm{mg}$ are far too high to be reduced to subtherapeutic levels by sustained daily treatment with rifampicin. Clearly then, the employment of a once monthly schedule of rifampicin administration exerts little if any effect on the rate of dapsone clearance. In the present study the levels of dapsone were not estimated, but it can be safely concluded that regular dapsone administration did not alter the rifampicin pharmacokinetic parameters. Thus concomitant combined regimen of dapsone with rif ampicin does not pose a pharmacokinetic drug interaction problem in the management of leprosy patients.

To what extent single administration of rif ampicin and daily administration of dapsone can influence clofazimine levels in leprosy cases has not been studied in the present study, but effect of dapsone and clofazimine alone and in combination has been assessd on the rifampicin pharmacokinetic parameters.

Except for significant reduction in $\mathrm{Ka}(P<0.01)$ and an increase in tp $(P<0.05)$ in $\mathrm{RC}$ group and significant reduction in 1 -hr serum rif ampicin level $(P<0.05)$ and Auc $(P<0.05)$ in RDC group, no other statistically significant alterations were produced perhaps due to opposing trends in other parameters.

Although not statistically significant, two basic opposing trends were observed. While clofazimine showed the tendency of increasing the apparent volume of distribution coupled with a tendency to reduce the rate of elimination, dapsone exerted an opposing influence. Since clofazimine reduced Ka significantly in addition to the trend of increasing avd and MCR, the logical outcome should have been a reduction in $t \frac{1}{2}$ and Auc, but on the contrary a trend of increase was noted, perhaps best explained by the trend of reducing the rate of elimination.

On the other hand, dapsone reversed the trends in the opposite direction. A trend of reduced apparent volume of distribution associated with a tendency to increase the rate of elimination was seen. Thus the former resulted in a trend of increase in Cmax and Auc of rifampicin, while the latter, in addition to an increase in MCR, accounted for a trend of increase in $t \frac{1}{2}$ of rifampicin; thus overall effect was negligible.

Consequent to these opposing influences, combined effect of dapsone and clofazimine resulted in a trend of reduction in $\mathrm{Ka}$ and increase in tp of rif ampicin. Added to this was the trend of an increase in MCR, avd and Ke accounting for the tendency of decrease in Cmax and $t \frac{1}{2}$ and overall statistically significant reduction in Auc $(P<0 \cdot 05)$.

Of the three groups, both RDC and RD were homogenous groups. Auc $/ t^{\frac{1}{2}}$ 
ratio of rifampicin in $\mathrm{RC}$ group was comparatively higher than in $\mathrm{RDC}(P<0 \cdot 05)$ and $\mathrm{RD}$ group $(P<0 \cdot 001)$. While comparing with $\mathrm{RD}$ group rifampicin avd and Ka were relatively less $(P<0.001 ; P<0.05$ respectively $)$ in RC group, the former resulting in increased $\mathrm{Cmax}(P<0 \cdot 01)$ despite a reduced $\mathrm{Ka}$ and thus resulting in an increased Auc $/ t \frac{1}{2}$ ratio even in the pre-regimen phase $(P<0 \cdot 01)$.

On the other hand except for Auc $/ t \frac{1}{2}$ ratio $(P<0.05)$, both $\mathrm{RDC}$ and $\mathrm{RC}$ groups were homogenous in the pre-regimen phase. And in post-regimen phase while clofazimine showed the tendency of reducing rifampicin $\mathrm{Ka}(\mathrm{P}<0.05)$ and increasing MCR $(P<0.02)$, dapsone was found to increase both the parameters. And this effect predominated even when dapsone was used concomitantly with clofazimine; thus RDC differed significantly from RC in these respects. Ultimately, it resulted in a prolonged $t \frac{1}{2}$ in $\mathrm{RC}$ group significantly different from RDC group $(P<0 \cdot 02)$.

\section{Conclusions}

Clofazimine reduced rifampicin absorption significantly resulting in delayed time to reach peak serum concentration and increased $t \frac{1}{2}$, but no significant change was seen in Auc, and Cmax because Ke was reduced significantly by clofazimine when used without dapsone in addition to insignificant increase in MCR.

Obviously, further studies are required to determine the time interval to be kept between administration of clofazimine and rifampicin so that it may not interfere with the absorption of rifampicin. In view of this, the following questions were raised:

(a) Whether it is appropriate to give clofazimine daily when it is known to have a long half life.

(b) Whether it would be rational to combine the monthly supervised dose of clofazimine $(300 \mathrm{mg})$ with rifampicin $(600 \mathrm{mg})$ in the light of the present findings. In view of this, whether it would be appropriate to increase the monthly dose of rifampicin to compensate for the 'clofazimine effect'.

\section{Some clinical impressions of Multidrug therapy (MDT) in leprosy}

The Poona District Leprosy Committee is running two leprosy control projects, one in the urban area of Poona and the other at Solapur. In these projects, by the end of December 1985, 4532 leprosy patients were given MDT. Of these, 1828 patients are multibacillary while 2704 are paucibacillary.

The standard regimen recommended by the WHO Technical Report Series $675^{9}$ is being followed for multibacillary as well as paucibacillary cases. The patients who have maintained regularity in treatment have shown clinical as well 
as bacteriological improvement. They did not show major side-effects/toxicity. A detailed analysis of the data is being undertaken. However, a few cases in whom interesting clinical findings were observed are reported here.

In 21 multibacillary cases, the bacteriological index started falling initially and after it dropped to $1 \cdot 0 / 1.5$ it remained static, even after continuing MDT, though they showed definite clinical improvement. The pigmentary changes and the ichthyotic changes seen during clofazimine therapy persist for more than 2 years after stopping clofazimine. In a few patients, pigmentation due to clofazimine therapy is not pronounced, though supervised clofazimine therapy is confirmed. The reason for this is not known.

In 20 paucibacillary patients, those previously treated with dapsone monotherapy and later put on MDT did not show much clinical improvement in respect of the patches, while clinical response in new untreated paucibacillary patients treated with MDT is excellent, as observed in the disappearance of the patches. It is the observation of some of our colleagues that if MDT is discontinued after 6 months, patients report back within 1 year with relapse in the form of new patches.

\section{Acknowledgments}

The authors acknowledge the assistance of Dr V H Jadhav and the staff of Dr Bandorawalla Leprosy Hospital, the Managing Director and Dr M V Panse of Hindustan Antibiotics Limited, Pune, for providing certain facilities, and the cooperation given by the leprosy patients who participated in this study.

\section{References}

1 Huff BB (ed). Physician's Desk Reference, 35th Edition, Rifadin, 1981: 864.

${ }^{2}$ Bullock WE. Rifampicin in the treatment of leprosy. Review of Infectious Diseases, 1983; 5 (Suppl 3): 606-613.

${ }^{3}$ Gilber RH et al. The effect of rifampicin on dapsone metabolism. Proc West Pharmacol Soc, 1975; 303

${ }^{4}$ Kenny MT, Strates B. Metabolism and pharmacokinetics of the antibiotic rifampicin. Drug Metab Rev, 1981; 12(1): 159-218.

${ }^{5}$ Russel D A et al. Acedapsone (DADDS) treatment of leprosy patients in the Karimui of Papua New Guinea: status at six years. Am J Trop Med Hyg, 1975; 24(3): 485.

${ }^{6}$ Shepard CC et al. Further experience with the rapid bactericidal effect of rifampicin on mycobacterium leprae. Am J Trop Med, 1974; 23(6): 1120-24.

7 Viratenen S, Tala S. Serum concentration of rifampicin af ter oral administration. Clin Pharmacol Ther, 1974; 16: 817-820.

${ }^{8}$ Waters MFR et al. Rifampicin for lepromatous leprosy; nine years' experience. Brit Med J, 1978; 1: 133 .

9 WHO Technical Report Series No. 675, 1982. Chemotherapy of Leprosy for control programmes. 24. 